\title{
INTEGRATION OF PHOTOVOLTAIC TO THE GRID USING HYSTERESIS CURRENTCONTROL
}

\author{
Reetesh Kumar Maurya ${ }^{1}$, Dr. Imran ${ }^{2}$

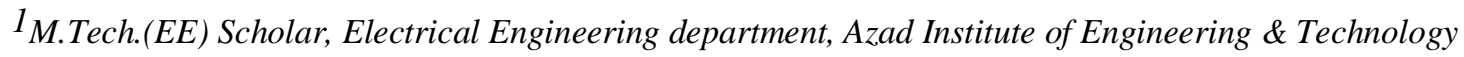 \\ Lucknow, India \\ ${ }^{2}$ Assistant Professor, Electrical Engineering department, Azad Institute of Engineering \& Technology \\ Lucknow, India \\ ${ }^{1}$ Email-as-rtsmaurya335@gmail.com \\ ²Email-pe.imran@gmail.com
}

\begin{abstract}
This research paper deals with the increasingly urgent energy issues; the world attaches great importance to begin the development of new energy and related technology. At present, large scale photovoltaic power generation and scale of renewable energy has become parts of development strategy, meanwhile it is the way to guide the development of photovoltaic industry. However, because of its own characteristics different from conventional power generation grid connected $P V$ power station and its security, stability, reliable operation become new challenges which power grid and PV power plant need to face. Grid connected voltage source inverters are essential for the integration of the distributed energy resources. However, due to the small capacity andintermittent nature of the renewable sources, it is extremely difficult to integrate them in the existing grid system. This project has taken an attempt to design a control method for three- phase grid-connected inverter system for distributed generation application. Themethod is hysteresis current control along with PI control. Hysteresis current control is a commonly employed method for power control of VSI. The control procedure is implemented in analog circuit using Op-amps and other ICs. This controller will generate pulses to fire the inverter in order to control the current output of the inverter. The control method along with the PI controller provides robust current regulation and achieve unity power factor. In addition, in this project development of controller in D Space is attempted. Simulation and experimental results are provided to demonstrate the effectiveness of the design.
\end{abstract}

Keywords: Photovoltaic power generation, Renewable energy, $\mathrm{PV}$ power plant, Hysteresis current control.

\section{INTRODUCTION}

Now-a-days power systems observing to the Smart Grid concept, has more andmore integration of DES (Distributed energy resources). It is based on clean energysources like solar energy. The integration of these resources increases the reliability andthe ability of power systems. Due to this emission of greenhouse gases can be seriously reduced. Voltage source inverters (VSI) are power electronics circuits used to line the DES with the power system. Grid connected VSIs are normally operated by controlling its output power, two possible control schemes can be applied either voltage or currentcontrol. The phase angle and amplitude of the output voltage are controlled according to the desired output power by voltage control. For the current control, the current injected bythe inverter is directly controlled to produce the desired output power. 


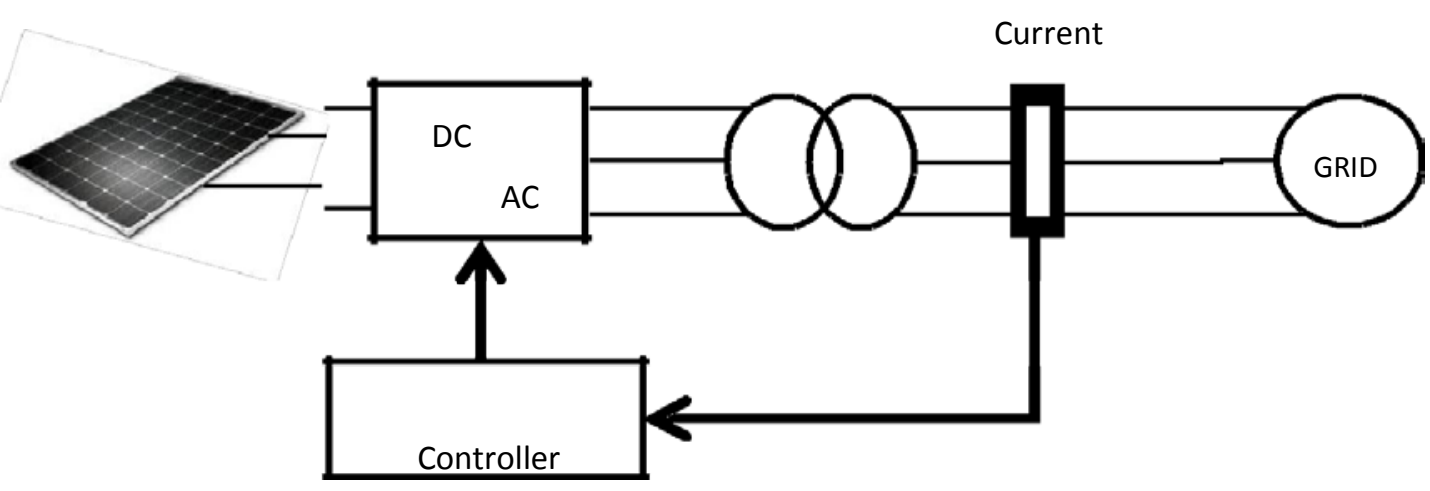

Figure 1.1 Layout of grid connected PV system

The contribution of renewable power sources to the total power generation becomes more and more significant because of their kind nature to the environment. These sources have become important because of the steady expansion in energy consumption and the deregulation of the utility. Schemes based on PV array have also been mostly employed for feeding power to the utility network. There are number of benefits for both the company and the consumer by integration of PV resources. These resources have longbeen proved to be advantageous in peak shaving and in loss reduction of power distribution systems. In such schemes, a three-phase inverter interposed between the PV source and the utility grid is necessary.

The voltaic effect of the solar light is applied frequently in these aspects: DC powersupply, AC power supply of the stand-alone inverters and grid-connected inverters. Thebattery is often used in the DC power supply system and the stand-alone inverter systembecause the PV array cannot supply the power continuously 24h a day. The grid- connected PV system does not require a battery because the grid can store the powergenerated by the PV array. However, it's a shame that the PV array loses the outputcapability when the insulation is weak or it is night, which forces the whole system to beremoved from the grid The features desirable for such inverters are low linecurrent distortion with high power factor, high efficiency and high switching frequencies. Hysteresis Current Control (HCC) was initially applied as an analog controller and it is frequently used for grid connected inverters configuration reflecting its fast transient response, good accuracy, implementation simplicity and fundamentally over-current protection. Common Hysteresis Current Control has two main disadvantages, the variable switching frequency depending on the load characteristics and the degradation of its accuracy when all digital applications are required. Numerous adjustments to the commonmethod have been started to overwhelm those problems [49]; most of the proposedmethods seek for a constant switching frequency present better performance than common method. Most of the modified strategies of Hysteresis Current Control offer better performances than the common one when they are implemented using analog logiccircuitry.

\section{A. PRINCIPLE OF THE CURRENT CONTROLLER}

The scheme composes of a three-phase inverter with a line filter and a three-phaseac grid. The VSI consists of six insulated gate bipolar transistors (IGBT) S1-S6 with a reverse diode in antiparallel across each device. The IGBTs in the three half-bridgesfor phases a, b, c of the inverter are numbered as S1 and S4, S3 and S6, and S5 and S2respectively. A PI controller in series with a hysteresis block implements the current control of the VSI shows the control structure of the proposed current controller. Theobjective of the controller is to force inverter output current to track 
the reference currentthat is derived from the grid voltage and at the same time to obtain a better undistortedcurrent waveform with low total harmonic distortion (THD).

The current control is achieved by comparing a reference current signal with actual inverter-output current, thus generating an error signal. The error signal is processed by a PI controller. The output of the PI controller is fed to a hysteresis current controller. The rigid band hysteresis current controller switches the power circuit to maintain the current between upper and lower bound values. Whenever the error reaches one of the two values, the power circuit is switched so that the current begins to move backwards in the other direction. In this way, the current is controlled to stay between two bounded values. The output of the hysteresis block is the gating signal, which is fed to thedriving circuit. The real and reactive power can be controlled by varying the magnitude and phase-angle of the reference current signal.

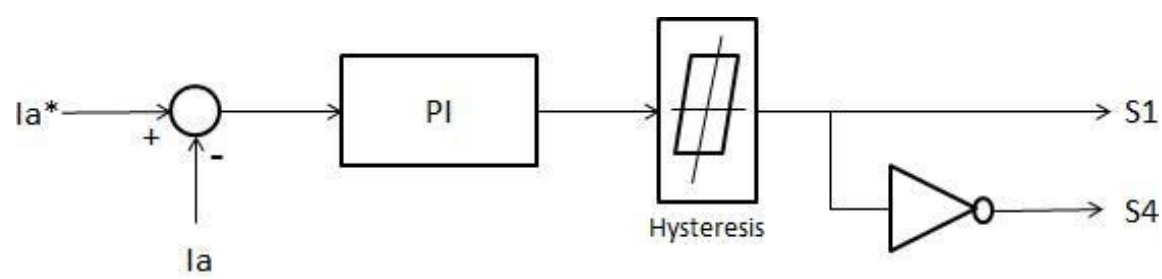

la
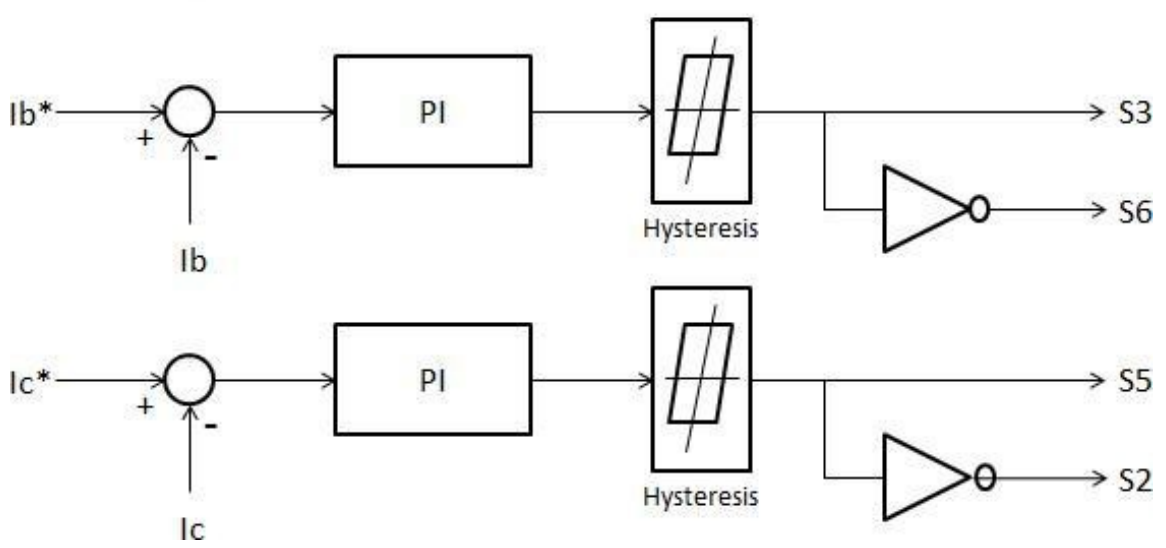

Figure 1.2 Hysteresis and PI control structure

\section{LITERATURE SURVEY}

Among multiple functions of grid connected systems, the current control plays one of the most important roles. The performance of the complete system largely depends on thequality of the applied current control strategy.

Earlier, proportional (P) control was attempted for such inverters, but such a control has an inherent steady-state error. The steady error found in a $\mathrm{P}$ controller was subsequently eliminated with an integral component added to the transfer function. The average value of current error can be reduced to zero at specified rate with such an integralcomponent. Nevertheless, the transient response of such proportional-integral (PI) controller is limited by the proportional gain. The gain must be set at a value such that theslope of the error is less than the slope of the carrier saw tooth waveform required for generating the firing pulses of the inverter. This results in an error under transient conditions. Later, an average current mode control (ACMC) was also attempted. ACMC was found to be an improvement of PI control technique because of an additional derivative component, which improves the gain of the regulator at the switching frequency.

This method has the problem of high frequency sub-harmonic oscillations with current mode control. 
ACMC has relatively fast transient response, with a relatively fast removal of steady-state error. However, instability is reported under certain conditions.

Current control based on prediction of the required subsequent instantaneous current output was also attempted. Such a control gives a better performance only when the mathematical model is accurate, linear and time-invariant. Predictive controller is computationally intensive, and therefore requires a large control loop time-period. This results in low control bandwidth and poor transient response. An elaborate current controller based on $\mathrm{d}-\mathrm{q}$ rotating coordinates was also proposed. Nevertheless, this controlis not easily amenable to implementation using op-amps.

\section{CURRENT CONTROL TECHNIQUES}

Among multiple functions of grid connected systems, the current control plays one of the most important roles. The performance of the complete system largely depends on the quality of the applied current control strategy. It has to fulfill basic requirements, such as low harmonic distortion of the output current, high dynamic response, regulation of the dc-link voltage and, in a number of cases, provide bi- directional power flow. The desire to propose a current control strategy which combines most of these requirements has encouraged many researches in the last two decades. A large number of current controller techniques have been described for different applications, namely ac drives, active filters, uninterruptible power supplies, ac-dc converters, etc. These control strategies achieve the same basic steady-state goal of controlling the fundamental input or output current waveform; however they differ on the implementation complexity, dynamic response and output current harmonic contents. Although the existing current control techniques vary from very simple hysteresis methods to complex analytical approaches, they are all based on the same basic principle. The load current is controlled by correctly modulating the converter input/output voltage.

One of the earliest introduced current control approaches based on this comparison technique is the ramp-comparison controller. It compares the control signal generated according to the current error to a triangular carrier waveform, to generate the switching states. The main advantage of this concept is that the inverter operates at a fixed switching frequency defined by the frequency of the triangular carrier waveform. However, the system response is affected by stability requirements of the feedback loop, which also depends to load parameters. Moreover, it performs an inherent phase and amplitude error even in steady-state operation.

A new tendency of implementing current control techniques into direct digital controllers using microprocessors has been of particular interest. Moreover, new generations of microcontrollers and digital signal processors are released with higher processing capability and with additional number of peripheries. This trend has boosted the utilization of control schemes that demand complex on-line processing and stored elements. The Direct Power Control concept fits into these characteristics, since it requires an instantaneous calculation of the active and reactive powers that are compared to the desired references. The error signals are used to select from a stored switching tablethe optimum switching state. Another approach which is increasing force with the development of faster DSP devices is the predictive control. It calculates the optimum inverter voltage required to drive the actual currents according to the reference values. Although it gives optimum performance in terms of both response time and accuracy, it takes more calculations and requires a good knowledge of the load parameters. The dependency of load parameters is eliminated for the hysteresis control approach which uses hysteresis comparators to select the proper switching states based on the comparison of the current error with switching boundaries defining a hysteresis band. Although simpleand extremely 
robust, this control technique exhibits several unsatisfactory features such as varying modulation frequency over a fundamental period. A good performance concerning steady-state accuracy is obtained using synchronous reference frame transformation. Using rotating dq-reference frame theory, ac values become dc quantities and can be easily regulated using PI controllers. However, stability and dynamic performance are again influenced by load parameters.

Each of the existing current control techniques has its own characteristics and strengths, which makes it suitable for specific applications. Furthermore, properties associated to switching frequency, load current distortion and dynamic behavior usually contradict each other. Therefore, the choice of the most appropriate current control method means searching for the best compromise between these characteristics and the nature of the application.

\section{A. RAMP-COMPARISONCONTROL}

The ramp-comparison current controller uses proportional-integral (PI) error compensators and a fixed frequency triangular carrier to generate the gate signals of the converter power switches. Based on the phase current error $(\Delta \mathrm{Ig}, \mathrm{i})$ the PI controller derives the modulating signals (Uc,i) to be compared to the pulse-widthmodulator (triangular carrier) as shown in Figure 3.1

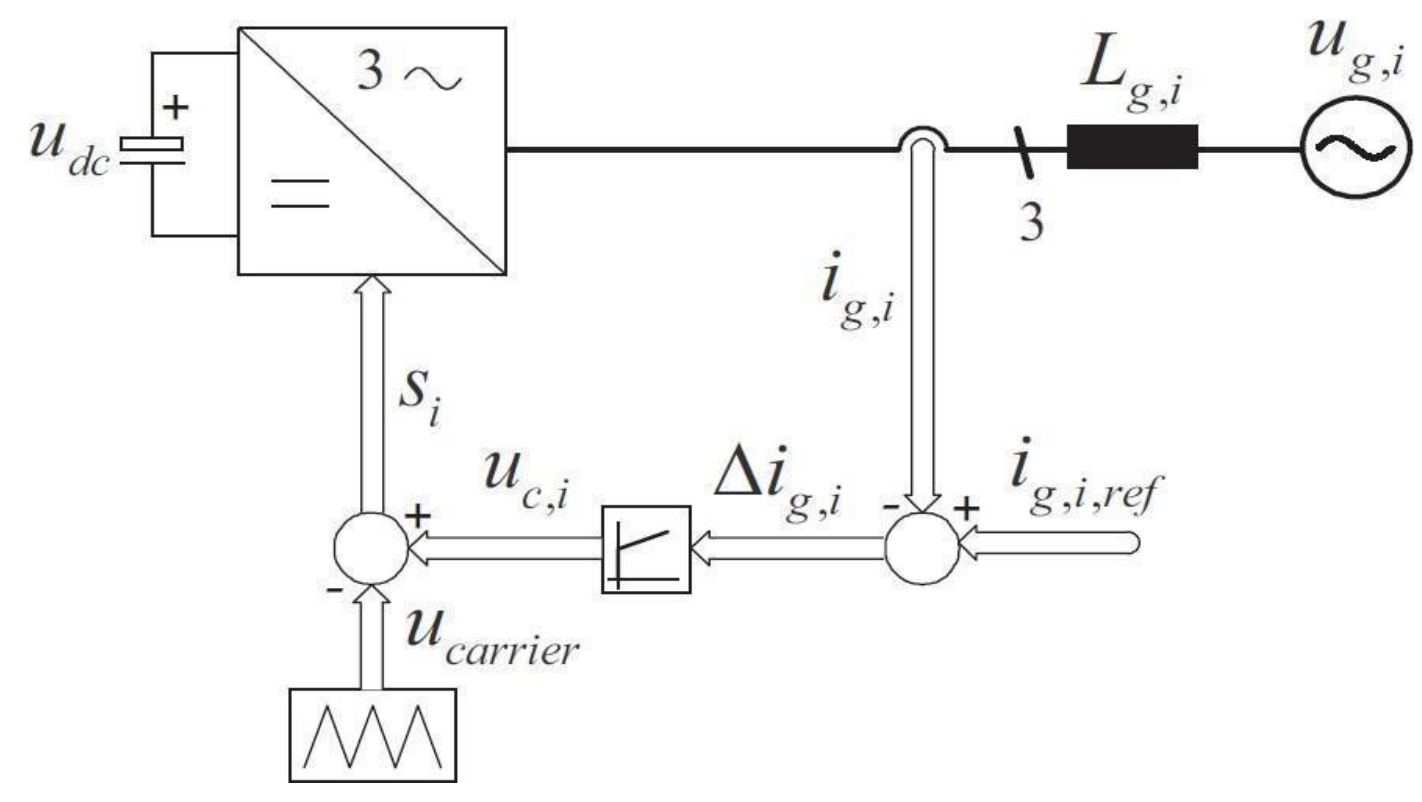

Figure 3.1: Ramp-comparison current control scheme

Some constraints are imposed on the controller design to guarantee the proper operation of the system. Even though the PI controller gain shall be selected high in orderto reduce the tracking error, it must remain low enough to avoid the amplitude of the control signal (uc,i) to exceed the carrier signal. Furthermore, the gain is also limited to ensure that the slope of the control signal is always less than the slope of the triangular carrier signal, thus avoiding multiple crossing which would result in increased switching frequency and $\backslash$ or switching losses.

\section{B. VOLTAGE-ORIENTEDCONTROL}


Voltage-Oriented Control (VOC) scheme uses the rotating dq frame theoryto ensure a zero steadystate output current error. By transforming ac phase quantities to dc components, the infinite dc gain of the PI controllers is able to lead actual dq currents tothe desired values without introducing static errors.

In the particular case of the VOC scheme the synchronous transformation is oriented suchthat the $\mathrm{d}$-axis is aligned to the grid voltage vector. The load current vector ig, is divided into rectangular components, where the component ig,d determines the active power whereas ig, $q$ controls the reactive power flow.

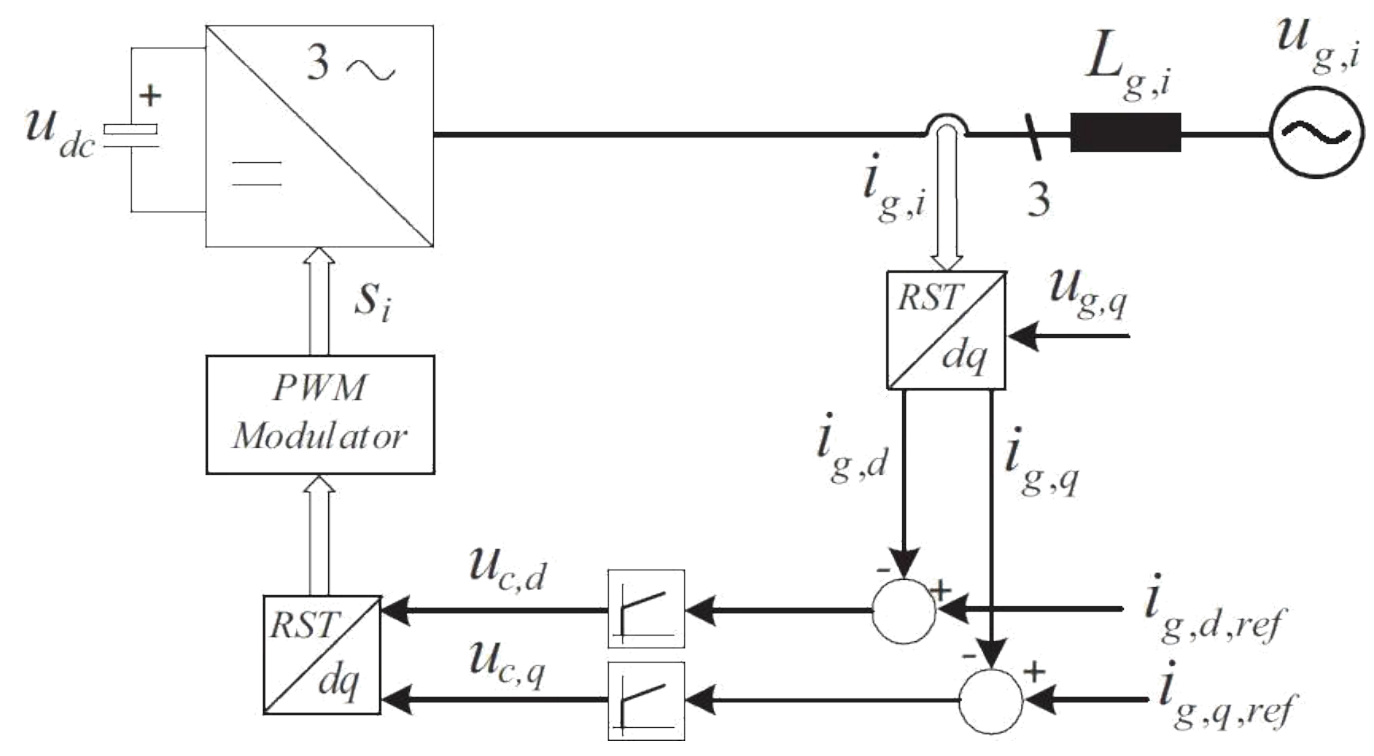

Figure 3.3 Voltage-Oriented Control scheme

\section{PREDICTIVE CURRENTCONTROL}

Due to the availability and continuous development of powerful and fast microprocessors, the interest in current control techniques which demand highcomputational effort is increasing. The performance of this type of controllers is risingproportionally to the speed and calculation power of new families of microprocessors. Thebasic idea of the predictive current controller is to perform a fast and accurate control loopthat selects the optimum control action among all possibilities, to fulfill a certain predefined criteria. This decision is based on the knowledge of actual variable measurements and load parameters.

The typical structure of a predictive current controller is shown in Figure 3.4. The "Load Model" block provides the actual load states to the "Prediction and Decision", which is considered the heart of a predictive control system. Based on the comparison of actual states and references, the optimum switching state is selected according to the decided criteria, which can be for example minimum switching frequency, minimum response time or minimum current distortion. 


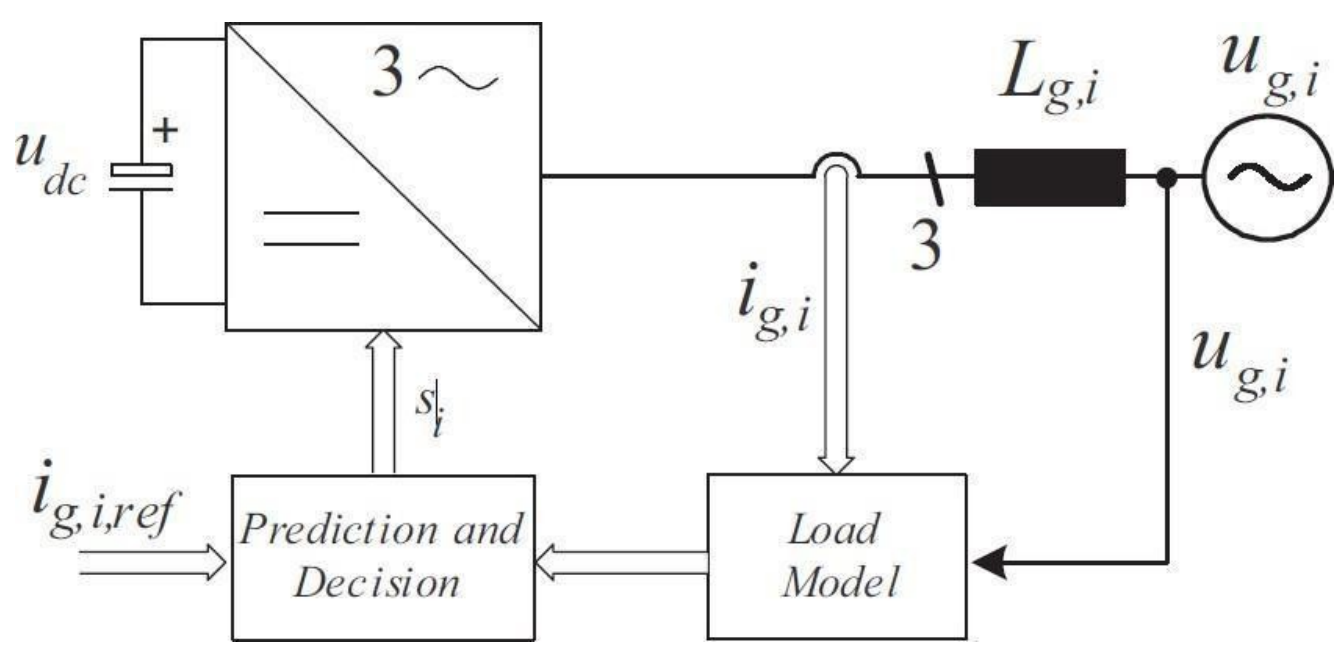

Figure 3.4 Basic structure of the Predictive current control approach

\section{HYSTERESISCONTROL}

The basic concept of the hysteresis current control is to switch the output voltage level (+udc to -udc for a two-level system) appropriately whenever the measured current goes above or below a given tolerance boundary. The current errors resulting from the comparison between measured currents and respective phase current references are controlled using three independent hysteresis comparators as illustrated in Figure 3.5 by the simplified diagram of a typical three-phase hysteresis current controller.

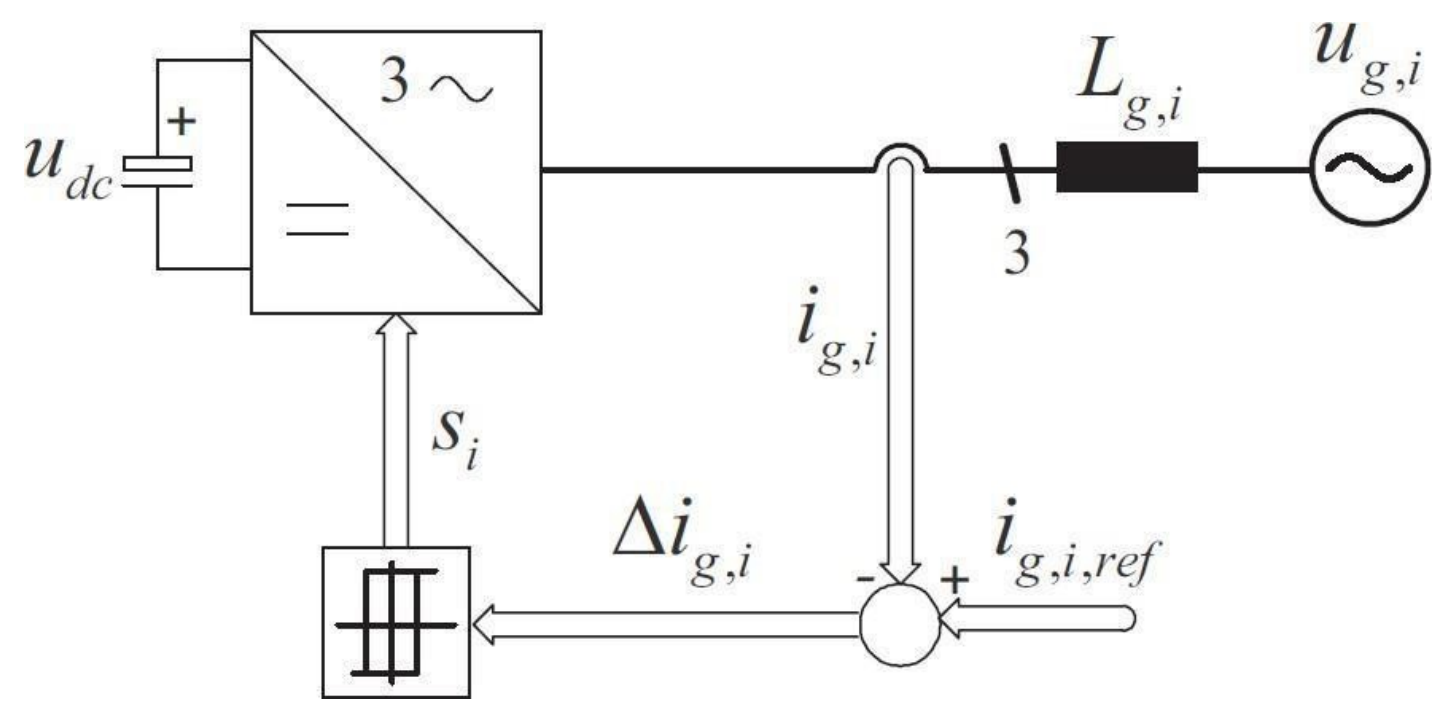

Figure 3.5 Hysteresis current control scheme

\section{CURRENT CONTROLLER}

To interface the PV system with the grid required a robust current control technique whose objective is to force the inverter output current to track the reference current which is desired from grid voltage. 


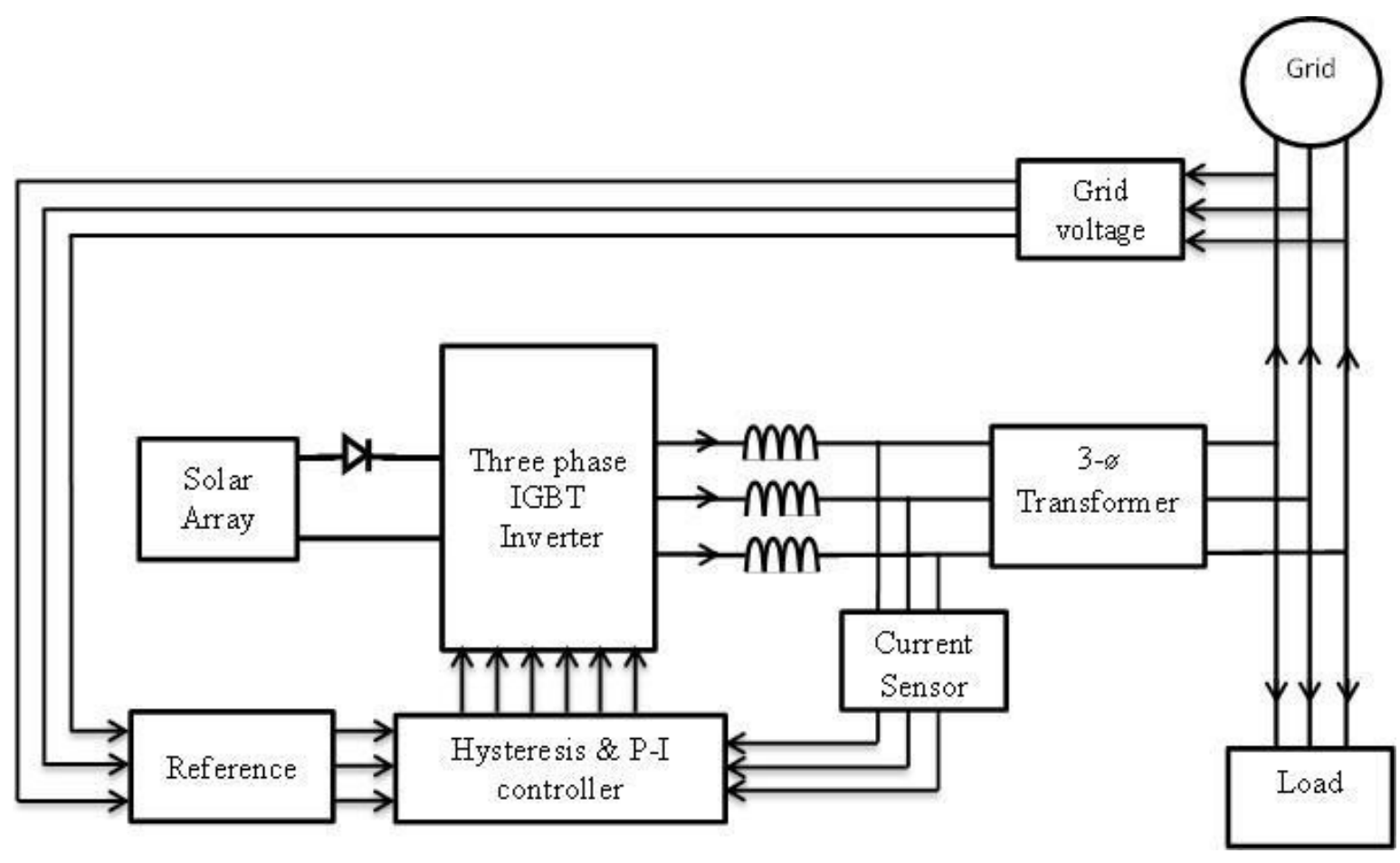

Figure 4.1 Overview of control strategy

Hysteresis current control is a method of generating the required triggering pulses by comparing the error signal with that of the hysteresis band and it is used for controlling the voltage source inverter so that the output current is generated from the filter will follow the reference current waveform. This method controls the switches of the voltage source inverter asynchronously to ramp the current through the inductor up and down, so that it follows the reference current. Hysteresis current control is the easiest control method to implement in the real time.

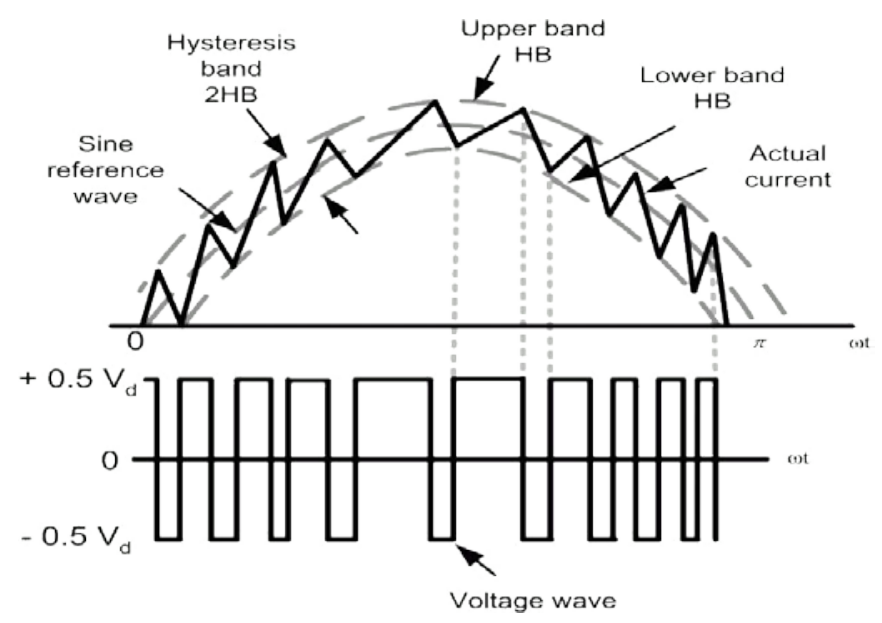

Figure 4.2 Hysteresis Band

In this method a feedback current control technique is used so that actual current continuously follows the command current limited by a hysteresis band. The control circuit generates a sine reference current wave od desired magnitude and frequency and it is comparedwith the actual phase 
current wave. As the current exceed a prescribed hysteresis band, the upper switch in half bridge is turned off and lower switch is turned on, as a result the output voltage transit from $+0.5 \mathrm{Vd}$ to $-0.5 \mathrm{Vd}$ ad the current starts to decay. In the same way as current exceeds lower band limit the lower switch is off and upper gets on.

This current control technique, which combines the simplicity of a classical PI control and the robustness of a hysteresis limiter. Thus, the zero steady state error of a linear PI controller and an excellent transient response feature of the hysteresis controller are together exploited effectively in this control. This combination allows a fixed switching frequency operation of the converter as against the required variable bandwidth operation of a conventional hysteresis controller. The proposed controller tracks the reference current even if there are changes in the hysteresis band. The proposed controller is very simple and has a low harmonic distortion and a very good dynamic response.

\section{SIMULTATION, EXPERIMENT SETUP \& RESULTS}

In this chapter result of the simulation, control setup for grid connected and for load and experimental investigation are presented. The simulation and experimental investigation was carried out based on system parameters given in Table 5.1 in MATLAB/Simulink environment. In this part output voltage and current waveforms of inverter have been shown.

\section{A. COMPONENTS PARAMETERSRATING}

Table 5.1 shows components and its rating used for simulation and experiment investigation.

\begin{tabular}{|l|l|l|}
\hline Components & Parameters & Ratings \\
\hline PV array & Power rating of one panel & $80 \mathrm{~W}$ \\
\hline & Open circuit voltage & $21 \mathrm{~V}$ \\
\hline Three phase inverter & Short circuit current & $4.8 \mathrm{~A}$ \\
\hline Grid & IGBT switch (semicron inv) & $700 \mathrm{Vdc}, 415 \mathrm{Vac}$ \\
\hline & AC source voltage(ph-ph, rms) & $415 \mathrm{~V}$ \\
\hline Filter & Source frequency & $50 \mathrm{~Hz}$ \\
\hline Load & Series inductor filter & $3 \mathrm{mH}$ \\
\hline & RL load resistance & $50 \Omega$ \\
\hline Transducer & RL load inductance & $20 \mathrm{mH}$ \\
\hline & Current sensor & $50 \mathrm{~A}$ \\
\hline
\end{tabular}

\section{B. SIMULATION OF GRID CONNECTED PVSYSTEM}

Figure 5.1 shows Simulink model of the system. Three phase auto transformer is proposed used to 
match the inverter output voltage the grid voltage. The load is taken as from nonlinear balanced load of $100 \Omega$ and $50 \mathrm{mH}$.

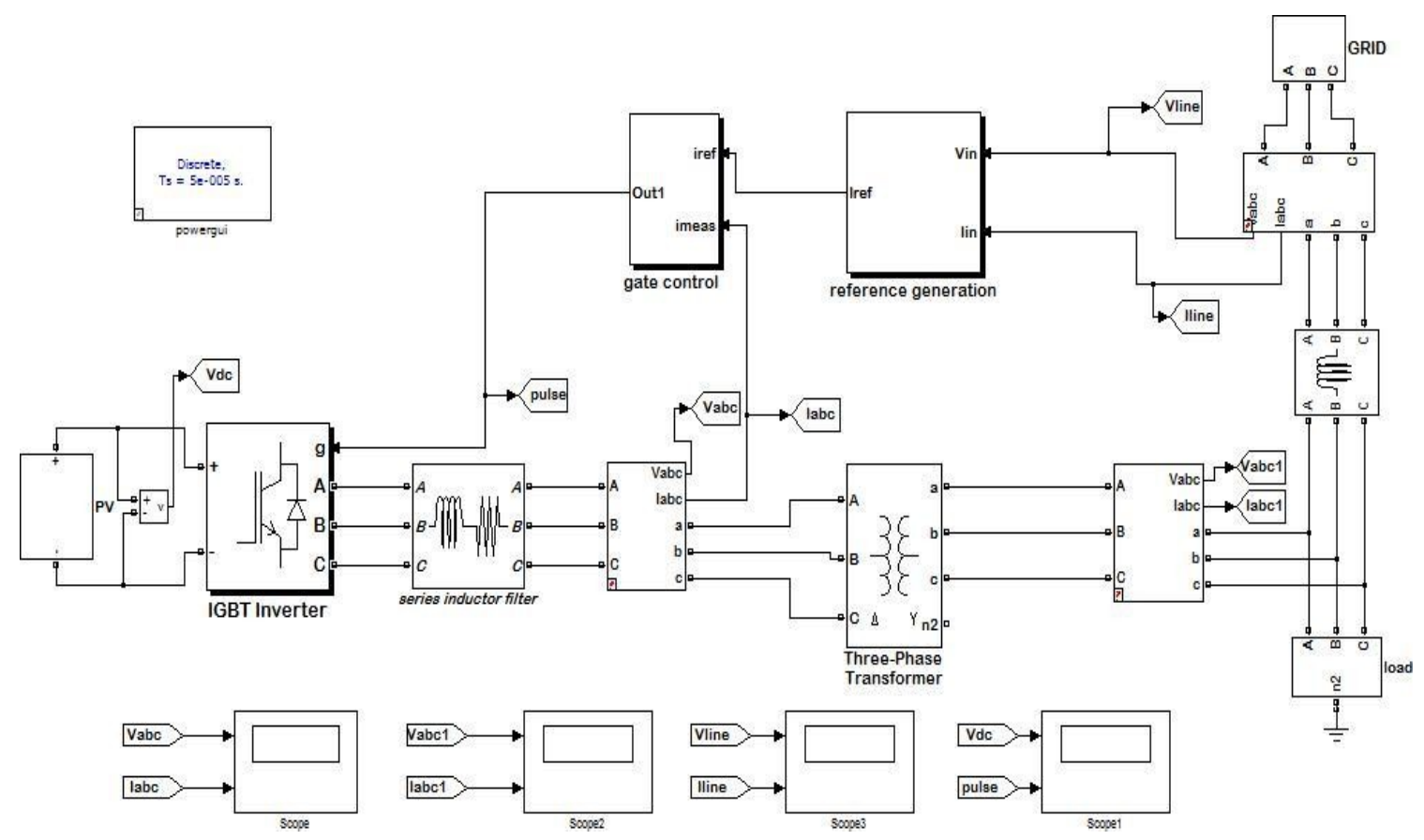

Figure 5.1 Simulation of grid connected PV system

\section{GRID VOLTAGE ANDCURRENT}

The grid voltage is maintained at $415 \mathrm{~V}$ (ph-ph rms) and the current flowing through the grid is pure sin wave of $50 \mathrm{~Hz}$ which will provide reference current waveform for the control circuit. Output waveform for the grid voltage and current is shown in figure 5.2.

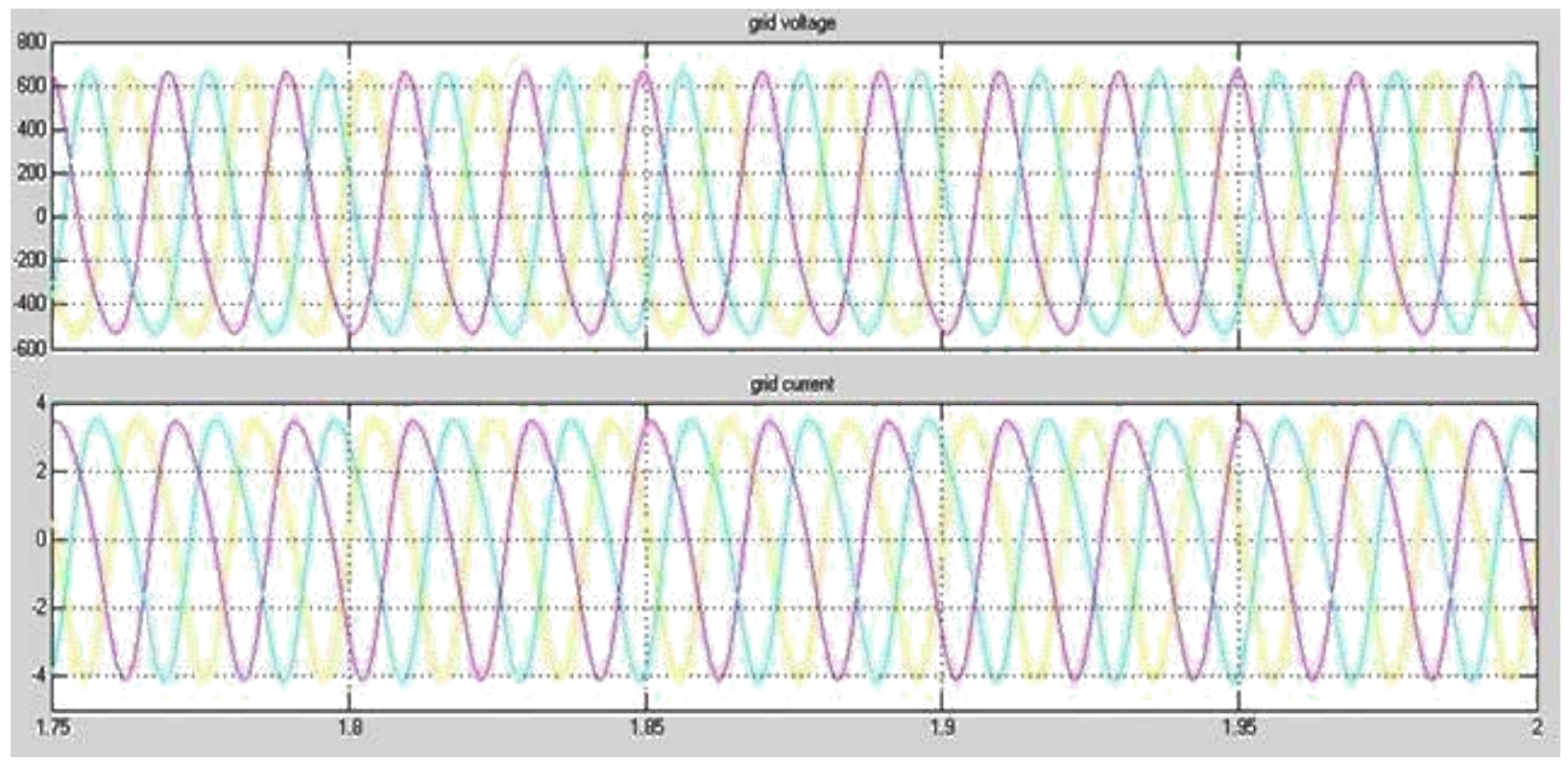

Figure 5.2 Grid voltage and current 


\section{PV OUTPUT AND FIRINGPULSE}

Figure 5.3 shows output across voltage and pulse generated from the controller PV Output voltage from PV is $35 \mathrm{~V}$ dc as two panels of $21 \mathrm{~V}$ are connected in series. The pulse generated from the controller has the switching frequency of $3 \mathrm{KHz}$.

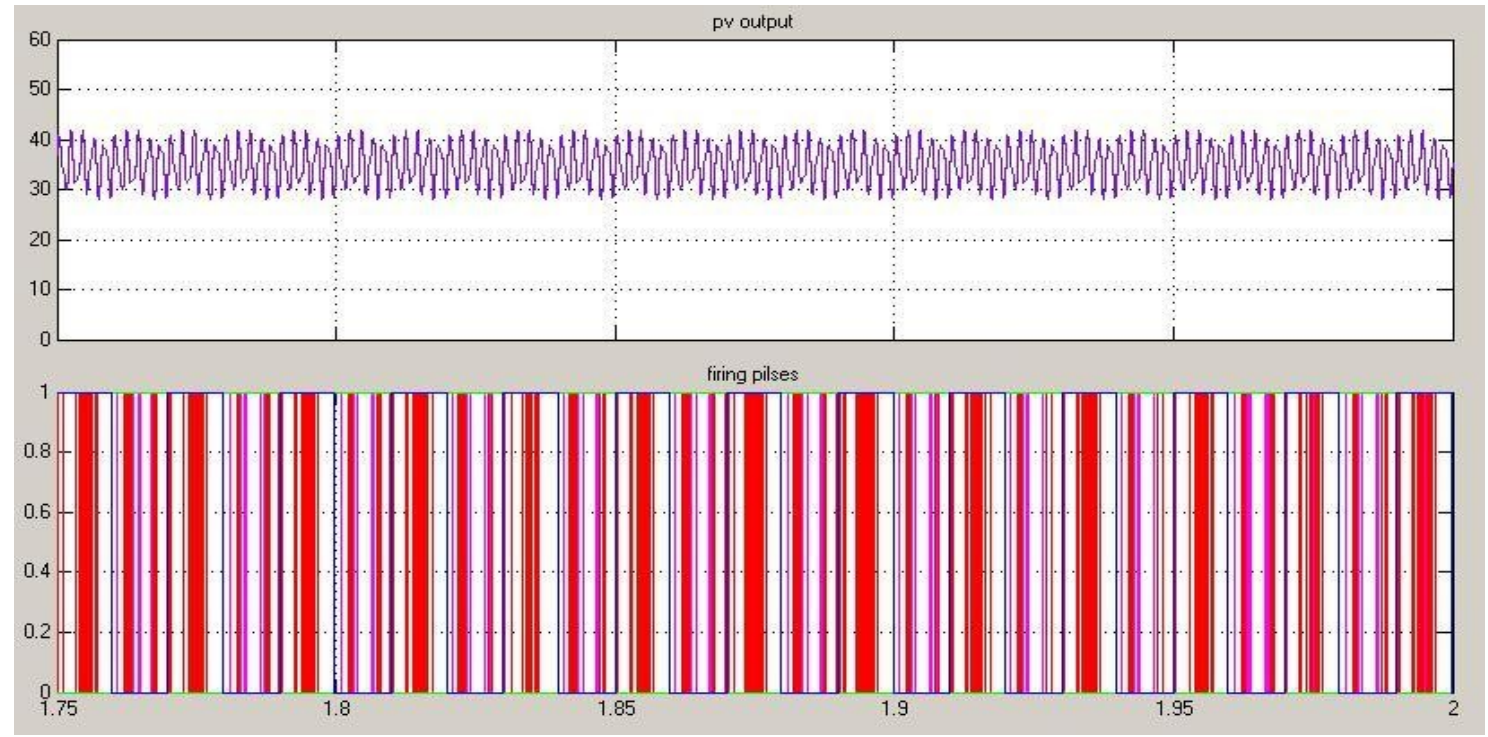

Figure 5.3 PV output and firing pulses

\section{E. INVERTER VOLTAGE AND CURRENT}

Here for linear load as the input dc supply is of 35 volt an AC voltage 34 Volt (ph- ph rms) obtained across output of the inverter which is further stepped up with the auto- transformer to match with the grid voltage. It is evident from figure 5.4 that waveforms are approaching sinusoidal, yet output current contains some higher order harmonics which can be eliminated by proper designing of filter.

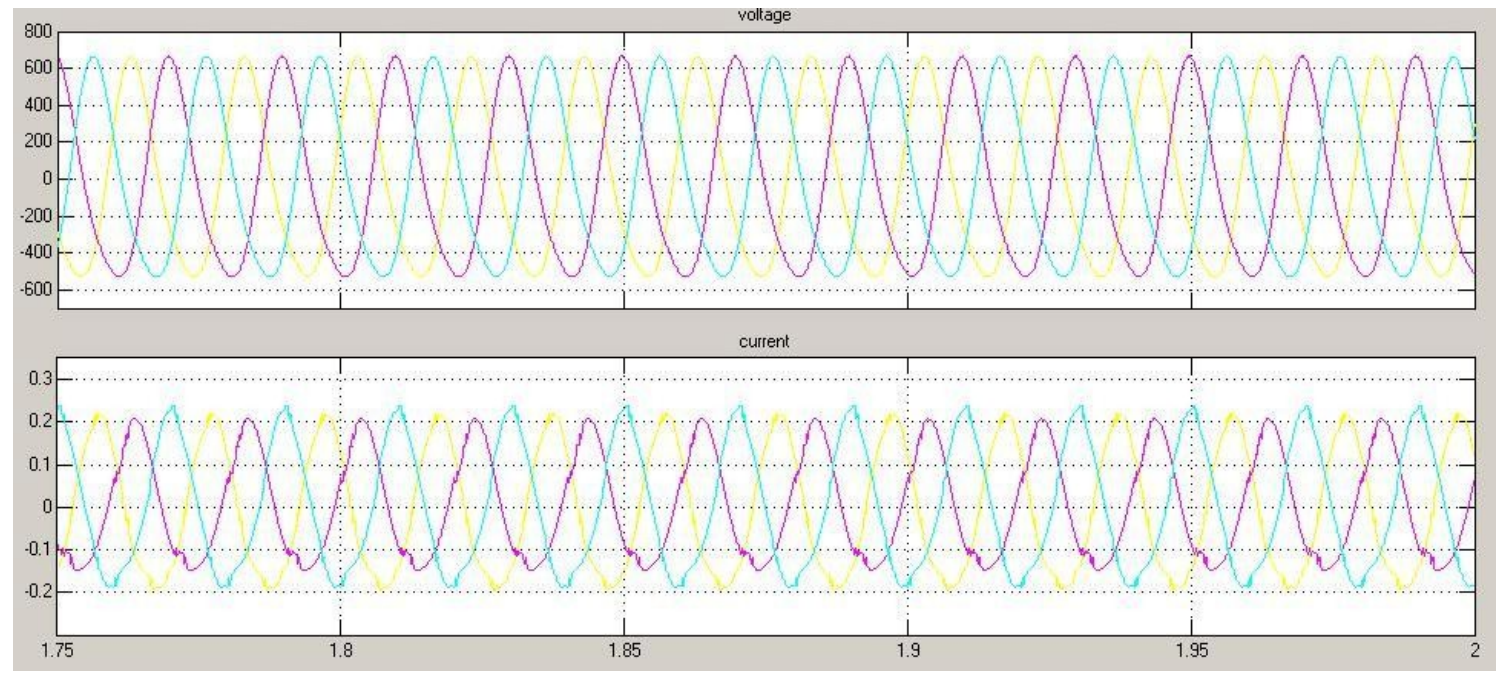

Figure 5.4 Inverter output with controller 
Now simulation has been performed for linear balance load by implementing the same controller without connecting the inverter to the grid. Figure 5.5 shows the inverter outputfor RL load of $50 \Omega$ resistance and $20 \mathrm{mH}$ inductance in each phase. The voltage output $24 \mathrm{~V}$ (ph-ph, rms) and the current drawn by the load is $0.12 \mathrm{~A}$.
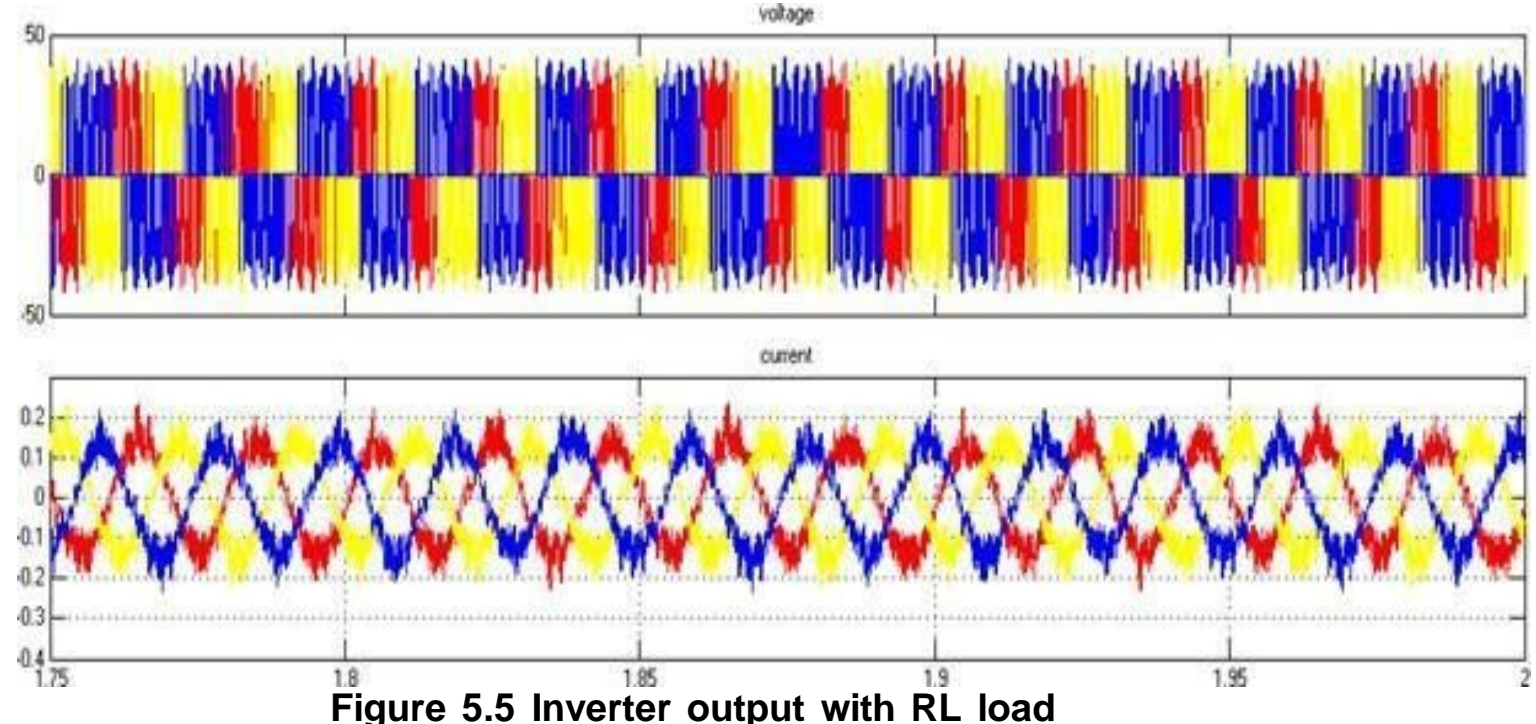

\section{F. EXPERIMENTALSETUP}

The whole setup of the experimental implementation is already described in previous chapters. The Semikron TM three-phase inverter is used to converter DC voltage to three- phase AC voltage for the RL load. The inverter can be fed by a maximum of $700 \mathrm{~V}$ DCvoltage, and output 20A rms AC current. And the inverter works at an absolute maximumswitching frequency of $20 \mathrm{kHz}$. An equivalent DC capacitor bank is provided in theSemikron TM. Although it's different from the capacitance designed in the simulationmodel, the experimental results show that the difference has little effect on the performance of the system. The inverter and other setup are shown in figure 5.6 and 5.7. The control circuit is used to fire the inverter connected to RL load while comparing gridvoltage and load current.

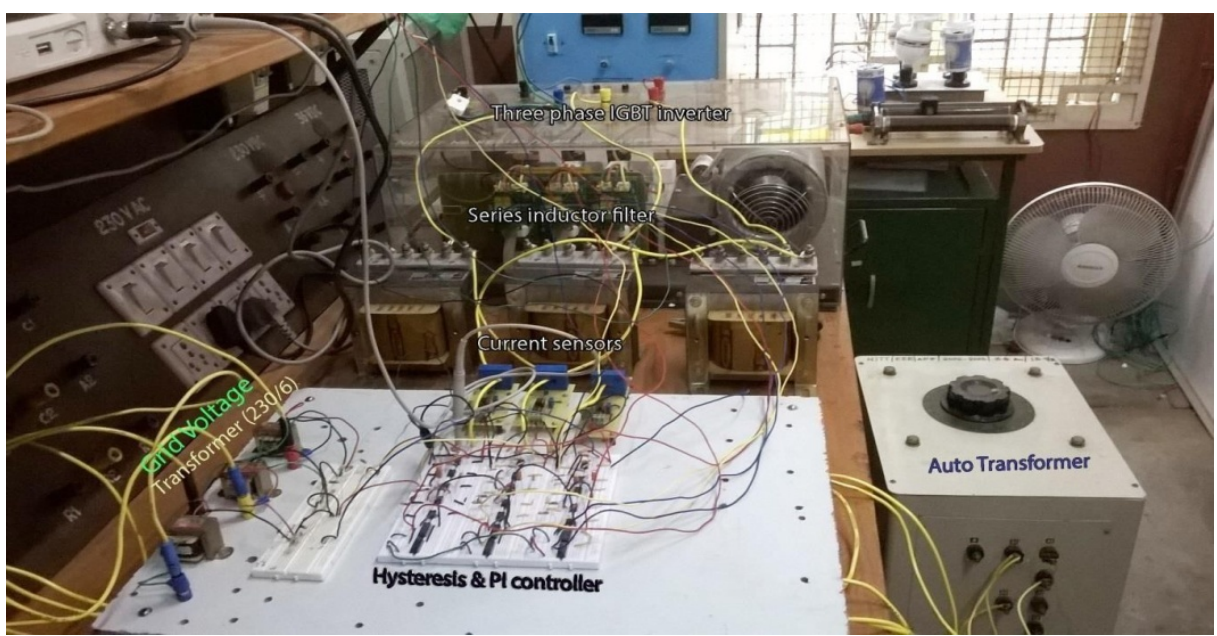

Figure 5.6 Control setup for grid connection 


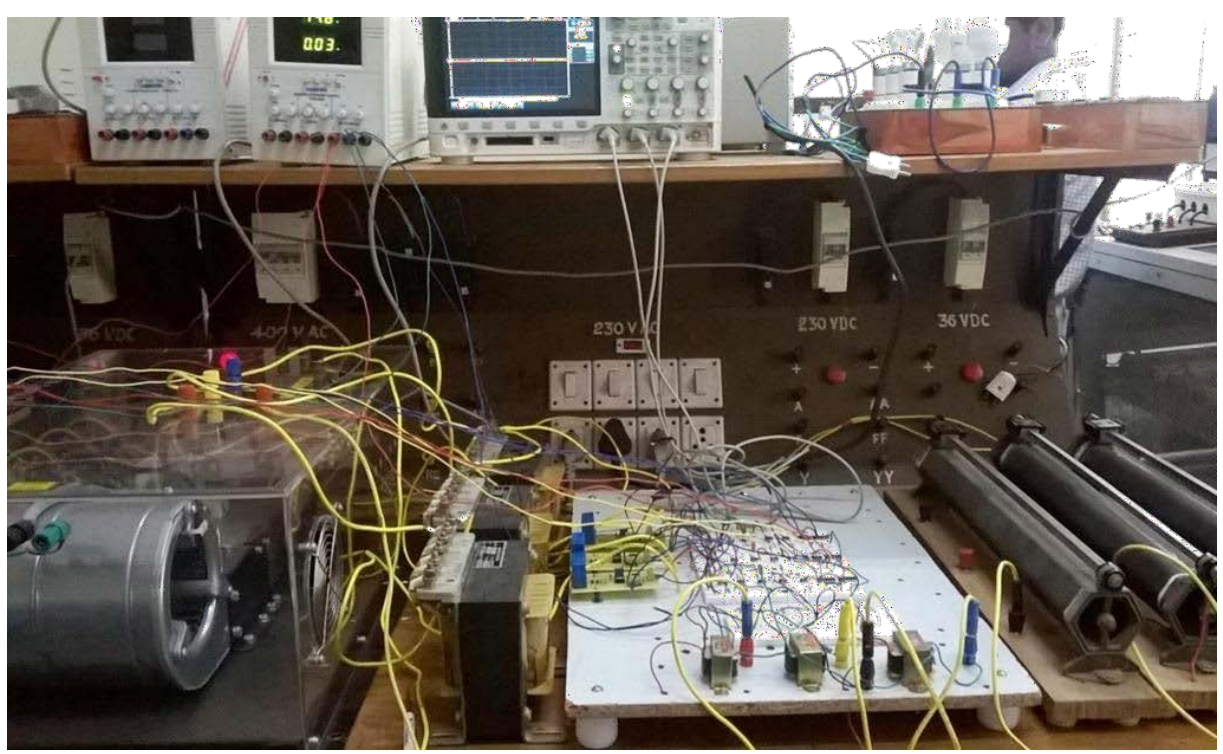

Figure 5.7 Control setup for RL load

\section{CONCLUSION}

This project has taken an attempt to design a control method for three- phase grid- connected inverter system for distributed generation application. The method is hysteresiscurrent control along with PI control for grid connected voltage source inverter. Followingconclusions can be drawn from the work:

> A current control technique, which combines the simplicity of a classical PIcontrol and the robustness of a hysteresis limiter. Thus, the zero steady state error of a linear PI controller and an excellent transient response feature of the hysteresis controller are together exploited effectively in the proposed control.

$>$ Moreover this combination allows a fixed switching frequency operation of the converter as against the required variable bandwidth operation of a conventional hysteresis controller.

$>$ The controller tracks the reference current even if there are changes in the hysteresis band. The proposed controller is very simple and has a low harmonic distortion and a very good dynamic response. Further, the proposed controller has no need of an accurate mathematical model and can be easily implemented using op-amps.

> This controller does not require a triangular carrier waveform as a classical PI controller for generating the triggering pulses. Hence the proposed approach does not set any limitation on slope of the error signal. It has been observed that changes in the hysteresis limits have not affected the injected current waveform in the new control technique.

$>$ Further, the proposed controller gives better dynamic. Such a dynamic response is required for peak power tracking of the PV source and offset the need of DC- DC conversion and DC link capacitor.

\section{REFERENCES}

1) Blaabjerg, R. Teodorescu, Z Chen, and M. Liserre, "Power Converters and Control of Renewable Energy Systems”, in Proceeding of International Conferenceon Power Electronics (ICPE’04), 2004.

2) Lai Jih-Sheng and Peng Fang Zheng, "Multilevel Converters-A new Breed of Power 
Converters”, IEEE Transactions on Industry Applications, vol. 32, no. 3, pp. 509- 517, 1996.I

3) N. S. Choi, J. G. Cho, and G. H. Cho, "A General Circuit Topology of Multilevel Inverter”, in Proceeding of Power Electronics Specialists Conference (PESC '91), 1991, pp. 96-103.

4) Habeebullah Sait, S. Arul Daniel, "New control paradigm for integration ofphotovoltaic energy sources with utility network” Electrical Power and Energy Systems 33 (2011) 86-93

5) M. Marchesoni, "High-Performance Current Control Techniques for Application toMultilevel High-power Voltage Source Inverters”, IEEE Transactions on Power Electronics, vol. 7, no. 1, pp. 189-204, 1992.

6) Zargari NR, Ziogas, Joos G. A two switch high performance current regulated DC/AC converter module. In: Proceedings of IEEE industry application social annual meeting, vol. 2; 1990. p. 929-34.

7) S. D. Round, L. Dalessandro, and J. W. Kolar, "Novel Phase Decoupling and Coordinating Tolerance Band Current Control for Three-Phase Three-Level PWM Rectifiers”, in Proceeding of European Conference on Power Electronics, Drives and Motion (PCIM'2005), Nuremberg, Germany, 2005, pp. 285-291.

8) K. Bose, “An Adaptive Hysteresis-Band Current Control Technique of a Voltage-Fed PWM Inverter for Machine Drive System”, IEEE Transactions on Industrial Electronics, vol. 37, no. 5, pp402-408, 1990.

9) G. Marcelo, J. Gazoli and E. Filho, "Comprehensive Approach to modeling and Simulation of Photovoltaic Arrays”, IEEE Trans. Power Electron. Vol. 24, no. 5,pp.11981208,May2009.

10) Pooya Ghani , Vahid Asadzadeh "Implementation of Three-phase grid-connected Technologies Conference (PEDSTC), 2011 2nd DOI: 10.1109/PEDSTC.2011.5742437 Publication Year: 2011 , Page(s): 305 - 310 Cited by: Papers (2)

11) Jaime Castelló Moreno, José M. Espí Huerta, Rafael García Gil and Sergio AlejandroGonzález, “ Robust Predictive Current Control for Three-Phase Grid- Connected Inverters”. IEEE Transactions on Industrial Electronics, vol. 56, no. 6, June 2009.

12) Dr. Qing-Chang Zhong "Control of Power Inverters in Renewable Energy and Smart Grid Integration". 